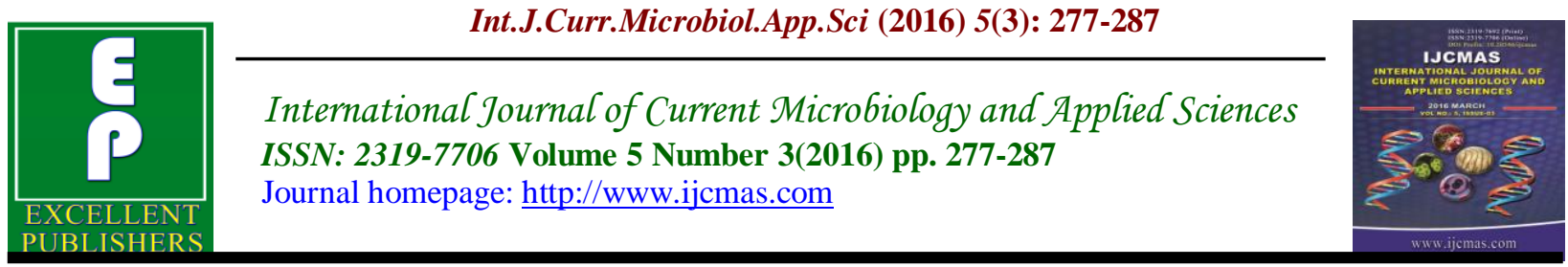

Original Research Article

http://dx.doi.org/10.20546/ijcmas.2016.503.034

\title{
Role of HLA-DQ Genotyping with Some Immunological Markers in Susceptibility for Infertile Males in Najaf Province
}

\author{
Hammadi A. Al-Hilali* and Haider J. Al-hasani \\ Department of Medical Microbiology, Faculty of Medicine, \\ Al-Qadisiya University, Diwaniya, Iraq \\ *Corresponding author

\section{A B S T R A C T} \\ Keywords \\ Infertility, \\ ASA, ANA, IL6, \\ Allele, \\ Genotype, \\ MR SPOT, \\ HLA DQB1. \\ Article Info \\ Accepted: \\ 15 February 2016 \\ Available Online: \\ 10, March 2016 \\ Infertility may be defined as the infertility of a couple to conceive after a period of \\ one year of intercourse without use of contraceptive. It is a worldwide problem that \\ characterized by multifactorial etiology. Genetic, physiology, infectious, \\ environmental factors and autoimmunity are reported as for as predisposal or even \\ causative agents of this condition. The current study has the aim of evaluation of \\ some immunological markers level and HLA DQB1 genotyping roles among \\ infertile male's patients. We have investigated HLA DQB1 HISTOSPOT in 75 \\ subjects by using. Fifty were infertile patients while others were apparently healthy \\ individuals used as a controls, then the serum level of IL6 and ASA was measure in \\ seminal plasma, were detected by ELISA technique and ANA was detected in sera \\ using indirect immune fluorecent assay test. The frequencies of *0303 allele a clear \\ difference between Azospermia and control groups, these differences are \\ significant (probability $=0.018$ ), while in the oligospermia patients with DQB1 \\ *0305 allele duplicates high compared to control and that the difference significant \\ (probability $=0.074)$. The study conclude that the (ASA, IL-6) and the presence in \\ the semen are signs of increase of patients with infertility, as well as the presence \\ of alleles DQB1 *0303 and DQB1 *0305 increases the probability of non- \\ production of sperm and decrease it in the count respectively.
}

\section{Introduction}

The World Health Organization (WHO) has determined Infertility a major problem affecting approximately married couples, it is defined as the inability to conceive after 1 year of unprotected sexual intercourse. Roughly, $30 \%$ of cases involve males, $35 \%$ involve female factor and the remaining represent unexplained or idiopathic infertility (WHO, 2010).
Male infertility's not an entity but reflects a variety of different pathological conditions, and the cause cannot be determined in most men investigated for infertility, the etiology of male infertility is obviously a multifactorial one, could be nutritional, physiological, pathological, accidental or even immunological (Khatoon et al., 2012). A high percentage of infertile men fail to impregnate their female counterpart because of lack of sperm (azoospermia) or low 
sperm count (oligozoospermia); infertility may also be due to abnormal sperm morphology (tetratozoospermia) and insufficient sperm motility (asthenozoospermia) (Feng et al., 2008). It has been estimated that infertility affects $13 \%$ to $15 \%$ of couples worldwide, with both male and female factors being present in many of these cases and in roughly half of these cases the defect can be traced to the males (Said, 2008). Cytokines play an important role as mediators of inflammation and progressive factors in development of infertility, various cytokines are considered as prime candidates for mediating infertility progression. ASA is abnormal production of immunoglobulin against sperm (antigens) leading to autoimmune disease with infertile. Antibodies are produced by the immune system to fight off foreign substances, like bacteria. ASA attaché to sperm and inhibit movement and their ability to fertilize. If directed specifically against the head of the sperm, they can prevent fertilization. Men or women may produce ASA, when exposure sperm antigen to immune system, ASA in male can occur in blood and seminal fluid, and then attach to the sperm surface (Eggert et al., 2000; Bohring et al., 2004). The ability of spermatozoa to penetrate the cervical mucus is inhibited by the existence of ASAs in the semen and /or in cervical mucus (WHO, 2010). ASAs can cause acrosome reaction abnormalities, inhibition of spermzonapellucida binding and prevention of embryo cleavage and its early development (Chiu and Chamley, 2004). ASA can affect sperm function at several different theories, and may act at three levels which included Pre-fertilization events at the level of sperm transport to the site of fertilization, Perifertilization events involving the binding of spermatozoa to the zonapellucida, the acrosome reaction, sperm adherence and fusion and Post-fertilization events such as pre-implantation embryo growth. Although there is a body of experimental evidence that antibodies raised against sperm antigen, it can react with eggs and embryos (Feng et al., 2008).

Antinuclear Antibody (ANA) is directed versus structures within the nucleus of the cell. Antinuclear antibodies (ANAs) are present in individuals whose immune system is ready to react against their own body tissues and result in production of auto antibodies. The tendency of the immune system to act against its own body antigens is referred to as auto immunity, the cause of autoimmune damage may be mainly due to either auto antibodies or autoimmune $\mathrm{T}$ lymphocytes. Nearly all autoimmune diseases are associated with circulating auto antibodies, which may also be found associated with non-related illnesses and in healthy individuals (Brackett et al., 2000).

Interlukin-6 is a multifunctional cytokine produced by both lymphoid and nonlymphoid cells. IL6 is polypeptide mediator regulating the immune response, the acute phase reaction and hematopoiesis. Mature IL6 is a glycoprotein (184 amino acids) with a relative molecular mass of $23-32 \mathrm{KDa}$ (Hirano and Kishimoto, 2004). IL-6 is an interleukin which is work as proinflammatory and anti-inflammatory cytokine. In humans, it is encoded by the IL6 gene (Ferguson et al., 1998). After injury or infection, specially burns or other tissue harm that causes inflammation, macrophages \& $\mathrm{T}$ cells were stimulate immune response by releasing IL-6. It is also contribute in fighting infection (Naz and Kaplan, 2004).The action of IL-6 in testis is reduces transferrin secretion in Sertoli cells. Moreover, IL-6 inhibits spermatogenesis and reduces sperm motility, increased level it in seminal plasma have been reported to be associated with 
infertility (Hirano and Kishimoto, 2004).The genetic factors can be further extended to involve genes located within the major histocompatibility complex (MHC), which is known as human leukocyte antigens (HLA) system. Such genes have been shown to be associated with a variety of diseases, especially autoimmune diseases, but have also been proposed to regulate reproductive processes in animals and humans (Hedges et al., 2000).Studies have revealed that microdeletions are more predisposing in male who are azoospermic and oligozoospermic (Brugh and Lipshultz, 2004). The human leukocyte antigen (HLA) system is a locus of genes that encode for proteins on the surface of cells that are responsible for regulation of the immune system in humans. This group of genes resides on short arm of chromosome 6 , and encodes cell-surface antigen-presenting proteins and has many other functions (Robinson et al., 2011).HLA-DQB1 belongs to the HLA class II beta chain paralogues. This class II molecule is a heterodimer consisting of an alpha (DQA) and a beta chain (DQB), both anchored in the membrane (Mackay and Rosen, 2000). It plays a central role in the immune system by presenting peptides derived from extracellular proteins. Class II molecules are expressed in antigen-presenting cells (APC: B lymphocytes, dendritic cells, macrophages) (Robinson et al., 2011).

\section{Materials and Methods}

\section{Patients}

Fifty infertile patient were selected and divided in two groups (25 Oligospermia and 25 Azospermia) were attending in the IVF \& infertility center in Al-Sadder medical City in Al-Najaf province, Iraq. The age of patients was range of 20-38 years and 25 fertile male with age matched healthy as controls, between December 2014and March 2015 were included in the study. We excluded the cases with varricocele.

\section{Methods}

The seminal fluid analyses tests were done to confirm the diagnosis of infertility, appearance, volume, $\mathrm{PH}$, viscosity and liquefaction of semen, sperm agglutination, morphology, motility and sperm count

Serum Il-6 was measured by ELISA (Cusabio / USA).

Antisperm antibody was calculated by ELISA. (Demeditec Dignostic/USA).

Anti-nuclear antibodies were determined by immunofluorscente (NOVA Lite / USA). Follow the manufacturer's instructions.

\section{Genotyping}

The genotypes of the HLA DQB1 alleles were determined by MR SPOT.DNA fragments extraction from EDTA blood specimens by using With Rabid ReliaPrep DNA extraction mini kit (Promega, USA), then the loci was amplified by using polymerase chain reaction (BAG health care (GERMANY). PCR amplifications were performed in Sprint Thermal-Cycler, programmed as following: denaturation, $96^{\circ} \mathrm{C}$ for $56 \mathrm{sec}$, annealing, $65^{\circ} \mathrm{C}$ for 15 second then elongation at $72^{\circ} \mathrm{C}$ for $20 \mathrm{sec}$ followed by 20cycles. After the PCR amplification process, the PCR plate containing biotin labeled amplicon was transferred to the MR.SPOT processor. MR.SPOT adds hybridisation buffer to each well and then transfers each amplicon plus hybridisation buffer to a test well containing an array of immobilized sequence-specific oligonucleotide (SSO) probes. The biotin labelled amplicon binds to those SSO probes 
that contain a Complementary target sequence and can then be detected by a colourimetric reaction. The resulting coloured dots in the bottom of each test well are photographed by MR.SPOT and the image was transferred into the HISTO MATCH software installed on the PC of the user. The image analysis program of the HISTO MATCH software determines the intensity of each spot in the array and compares it to the intensity of the background. From this data the positive and negative reactions were calculated. The pattern matching program of the HISTO MATCH software determines the HLA type of the sample based on the specific hybridization pattern. Figure(1).

\section{Statistical Analysis}

Statistical analysis was done by using SPSS (statistical package for social sciences) version 20 in which we use chi square test for categorical data and independent sample T-test for numerical data. Odds ratio for measuring strength of association. We set $\mathrm{P}$ value $\leq 0.05$ as significant.

\section{Results and Discussion}

\section{Demographic and Clinical Profile}

Demographic and clinical characteristics of infertile male and healthy control subjects are shown in Table (1). In which there are no significant differences between the patients and controls at all the parameters except seminal fluid parameter.

\section{The Role HLA-DQB1 Alleles in Studied Groups}

The loci of HLA class II (DQB1*0305, DQB1*0501) showed increased frequencies in oligozoospermia patients when compared to controls, were $(\mathrm{p}=0.044, \quad=0.049$ respectively), and the allele (DQB $1 * 0303)$ showed significant differences $(\mathrm{p}=0.018)$ between azoospermia patients and controls. But the difference was not significant for all other loci. Table (2)

The results revealed that three alleles may be considered important in the immunogenetic background of human male infertility; HLA-DQB1*0305, DQB1*0501 and HLA-DQB1*0303 alleles. The first and second allele showed an increase in one groups of infertility (oligozoospermia), while the third was restricted to azoospermia patients. Such findings may highlight the importance of HLA-DQ locus in conferring immunogenetic predisposition to develop infertility in human beings, therefore, HLADQ locus may harbours a risk gene for infertility, or such gene is in a linkage disequilibrium with specific alleles (i.e. DQB1*0305, DQB1*0501 and DQB1*0303) controlled by such locus. Back to some previous findings, investigators agree about the possible effects of HLA genes on male reproduction, and a study by Martin-villa et al. (1999) showed that HLA molecules are expressed on the spermatozoa's surface, following a cyclic pattern. Avendano et al., (2008) found that HLA transcripts were demonstrated in ejaculated sperm, and the fertile group showed significantly higher levels of HLA mRNA than the infertile group.

However, population based studies reported different associations between male infertility and HLA alleles in different populations. Aleksovski et al. (1988) demonstrated an increased frequency of HLA-A26, HLA-A28, and HLA-B18 alleles in idiopathic azoospermia and oligospermia Yugoslavian patients, while other studies reported further significant associations between idiopathic male infertility and HLA alleles, such as HLA-A33, HLA-B13, HLA- 
B44 and HLA-DR13, in Japanese male populations (Miura et al., 1998; Tsujimura et al., 1999; Takao et al., 2004). Such studies were based on serological typing of HLA alleles; while present study employed a molecular method that was based on a reverse hybridization after PCR amplification of DNA (HISTO SPOT method).

The development of molecular biology techniques based on PCR has greatly improved the accuracy and practicability of HLA typing, and there are several kinds of PCR-based HLA typing, such as, DNA amplification with sequence-specific primers (SSP), single-stranded conformation polymorphisms (SSCP), DNA chip technology, sequence-specific Oligonucleotide (SSO) and sequence-based typing (SBT) (Yang et al., 2010). Among these, HISTO SPOT has been reported to have an accuracy rate of $99.9 \%$, and final observed resolution of $85.6 \%$ for HLADQB1 alleles; therefore, it is considered rapid and easy-to-perform assay and yielded results fully concordant with other DNAbased tissue typing tests ( $\mathrm{Al}$-Yasiri et al., 2012).

Reviewing molecular typing of HLA-class II region in infertility revealed that DRB1*1302 allele is linked to susceptibility to non-obstructive azoospermia in Japanese men (Tsujimura et al., 1999). Moreover, certain microsatellite markers in the HLA class II region and at DRB1 and DQB1 loci show strong correlation with non-obstructive azoospermia, in particular, the frequency of DRB1*1302 and DQB1*0604 alleles was increased in Japanese men with nonobstructive azoospermia (Matsuzaka et al., 2004). Further molecular HLA typing revealed that HLA-A and HLA-B alleles showed no significant variation in idiopathic male infertility of Chinese patients (Zhou et al., 2011a; 2011b), while DQA1*0401 allele demonstrated a significant increase in immune infertility patients from China (Bao et al., 2011).

Such discrepancies can be better understood in the ground of race differences, because the distributions of HLA alleles display significant variation in different ethnic groups or even the same ethnic group living in various geographical areas (Shen et al., 2008), and Iraqi population share a similar interest (Ad'hiah et al., 2011). However, the geographical variation may highlight the importance of environmental factors (i.e. infectious agents) that can trigger the disease in individual carrying specific alleles and such alleles may be different in different populations (de Almeida and Holoshitz, 2011). Accordingly, type of infectious agent and HLA alleles may have their different interactions in different populations.

\section{Distribution of ASA and IL-6levels in Seminal Plasma among Azospermic, Oligospermic and Control Group.}

The result demonstrated significant elevation of IL-6 level in the group of oligospermic and azospermic (10.92 \pm 5.22$)$, (12.67 \pm 5.97$)$, respectively when compared with those of control group (8.65 \pm 0.76$)$. Table(3). Cytokines play an important role in intracellular communication. They are involved in physiological and pathological processes. Particularly in the mediation of inflammatory responses, and have important function in the reproductive physiology of women and men. Human semen contains a repertoire of cytokine whose effects on semen quality and sperm function (Andrews et al., 2009). IL-6 is a multifunctional cytokine produced by both lymphoid and non-lymphoid cells, IL6 is polypeptide Mediator regulating the immune response (Hirano et al., 2004).Increased IL- 
6 level cause inhibition of the production of sertoli cells transferrin. Transferrin is responsible for transportation of Iron through the blood-testis barrier, Iron one of the main element that stimulated dividing spermatocyte and spermatide this may be lead to decrease the sperm count (Celińska et al., 2006). The finding of Menkveld et al. (2011), who detected a decreased Iron supply as consequence of transferrin deficiency, result in decreased cell division and caused reduction in sperm count or oligozoospermia, have supported our findings in this aspect.

Our study data was in agreement with Bosmans et al. (2003) who observed that the elevate concentration of interleukin -1 , interleukin -6 and soluble IL-6 receptors in seminal plasma was associated to (azoospermia). The observation from our results may be hint of increased levels of IL6 in seminal plasma might be associated with infertility of men. There is little information about IL-6 interference with sperm production and semen quality. IL-6 increased in parallel to leukocyte counts and other potential markers of subclinical infection/inflammation in the same ejaculates, potentially interrelated with other cytokines e.g IL-8 (Hedger and Meinhard, 2003).

Data in the table (3) shows that there was a high percentage 6(24\%) Antisperm antibodies of infertile male with Azospermia and high significant $(\mathrm{p}=0.009)$ difference found when compared to control group infertility cases also 25 oligospermia males screened for seminal plasma anti-sperm antibodies, 4(16.0\%) where found positive, this mean significant statistical when compared it with fertile group, $(\mathrm{p}=0.037)$.

The role of ASAs in the cause infertility remain Ambiguous. Antibodies activities to spermatozoa has been showed in males, but their clinical significance remained debatable, although considerable data from both human and animal experiences suggest that ASAs can affect fertility in a variety of ways. There are various mechanisms that can affect the fertility potential of a male include an effect on sperm transport, sperm capacitation and acrosome reaction, spermegg interaction and, lastly, a possible systemic effect under which the presence of ASAs is only reflective of a general immune activation and fusion with egg vitelline membrane (Khatoon et al., 2012).

Table.1 Demographic and Clinical Characteristics of Infertile Male and Healthy Control Subjects

\begin{tabular}{|l|c|c|}
\hline \multicolumn{1}{|c|}{ Control } & Patient & Variables \\
\hline No. ( Male) & $50(25 / 25)$ & 25 \\
\hline Age range (mean) years & $20-38(25.3)$ & $21-40(28.6)$ \\
\hline Family history (+) \% & $6) 12 \%($ & - \\
\hline Smoking of infertile ( +) \% & $5) 10 \%($ & $2) 8 \%($ \\
\hline$\quad$ Seminal fluid analysis parameter & Abnormal & Normal \\
\hline Duration of infertile ( years ) & $1-10$ & - \\
\hline
\end{tabular}


Table.2 Association between Dqb1 Allele in Control, Oligospermia Andazospermia

\begin{tabular}{|c|c|c|c|c|c|c|}
\hline & & \multirow[b]{2}{*}{ Control } & \multirow[b]{2}{*}{ Oligospermia } & \multirow{2}{*}{$\begin{array}{c}\mathbf{P} \\
\text { value }\end{array}$} & \multirow[b]{2}{*}{ Azospermia } & \multirow{2}{*}{$\begin{array}{c}\mathbf{P} \\
\text { value }\end{array}$} \\
\hline & & & & & & \\
\hline \multirow{40}{*}{ DQB1 } & \multirow{2}{*}{ *0201 } & 0 & 1 & \multirow{2}{*}{0.312} & 2 & \multirow[t]{2}{*}{0.149} \\
\hline & & $0.0 \%$ & $100.0 \%$ & & $100.0 \%$ & \\
\hline & \multirow{2}{*}{ *0202 } & 2 & 1 & \multirow{2}{*}{0.552} & 0 & \multirow[t]{2}{*}{0.149} \\
\hline & & $66.7 \%$ & $33.3 \%$ & & $0.0 \%$ & \\
\hline & \multirow{2}{*}{ *0203 } & 2 & $\mathbf{0}$ & \multirow{2}{*}{0.149} & 1 & \multirow[t]{2}{*}{0.552} \\
\hline & & $100.0 \%$ & $0.0 \%$ & & $33.3 \%$ & \\
\hline & \multirow{2}{*}{ *0204 } & 4 & 2 & \multirow{2}{*}{0.384} & 1 & \multirow[t]{2}{*}{0.157} \\
\hline & & $66.7 \%$ & $33.3 \%$ & & $20.0 \%$ & \\
\hline & \multirow{2}{*}{ *0205 } & 1 & 2 & \multirow{2}{*}{0.552} & 0 & \multirow[t]{2}{*}{0.312} \\
\hline & & $33.3 \%$ & $66.7 \%$ & & $0.0 \%$ & \\
\hline & \multirow{2}{*}{ *0206 } & 2 & $\mathbf{0}$ & \multirow{2}{*}{0.149} & 2 & 1 \\
\hline & & $100.0 \%$ & $0.0 \%$ & & $50.0 \%$ & \\
\hline & $* 0200$ & 1 & 0 & 0212 & 0 & 0.312 \\
\hline & +0208 & $100.0 \%$ & $0.0 \%$ & 0.312 & $0.0 \%$ & \\
\hline & *0200 & 2 & 1 & & 1 & 0.552 \\
\hline & $\pi 0209$ & $66.7 \%$ & $33.3 \%$ & 0.552 & $33.3 \%$ & \\
\hline & & 2 & 3 & & 2 & 1 \\
\hline & $* 0301$ & $40.0 \%$ & $60.0 \%$ & 0.637 & $50.0 \%$ & \\
\hline & & 0 & 1 & & 5 & 0.018 \\
\hline & $* 0303$ & $0.0 \%$ & $100.0 \%$ & 0.149 & $100.0 \%$ & \\
\hline & $* 020$ & 1 & 0 & 010 & 0 & 0.312 \\
\hline & .0304 & $100.0 \%$ & $0.0 \%$ & 0.149 & $0.0 \%$ & \\
\hline & & $\mathbf{0}$ & 3 & & 2 & 0.149 \\
\hline & $* 0305$ & $0.0 \%$ & $100.0 \%$ & 0.044 & $100.0 \%$ & \\
\hline & $* 0306$ & 2 & 1 & 0552 & 2 & 1 \\
\hline & . 0500 & $66.7 \%$ & $33.3 \%$ & 0.552 & $50.0 \%$ & \\
\hline & $* 0501$ & 1 & 4 & 0049 & 1 & 1 \\
\hline & & $20.0 \%$ & $80.0 \%$ & 0.049 & $50.0 \%$ & \\
\hline & *0506 & 1 & 2 & 0552 & 1 & 1 \\
\hline & *0506 & $33.3 \%$ & $66.7 \%$ & 0.552 & $50.0 \%$ & \\
\hline & $* 0509$ & 0 & 1 & 0140 & 1 & 0.312 \\
\hline & FDOD & $0.0 \%$ & $100.0 \%$ & 0.149 & $100.0 \%$ & \\
\hline & $* 0509$ & 0 & 1 & 0.149 & 0 & 1 \\
\hline & ros09 & $0.0 \%$ & $100.0 \%$ & 0.149 & $0.0 \%$ & \\
\hline & $* 0601$ & 3 & 1 & 0207 & 3 & 1 \\
\hline & r0601 & $75.0 \%$ & $25.0 \%$ & 0.297 & $50.0 \%$ & \\
\hline & *0606 & 0 & 1 & 0149 & 1 & 0.312 \\
\hline & 0000 & $0.0 \%$ & $100.0 \%$ & 0.149 & $100.0 \%$ & \\
\hline & $* 0609$ & 1 & 0 & 0.149 & 0 & 0.312 \\
\hline & *0609 & $100.0 \%$ & $0.0 \%$ & 0.149 & $0.0 \%$ & \\
\hline & & 25 & 25 & & 25 & \\
\hline Hotan & & $100 \%$ & $100 \%$ & & $100 \%$ & \\
\hline
\end{tabular}


Table.3 Comparison of Asa and Il-6 Level in Seminal Plasma among Control, Azospermia and Oligospermic Group

\begin{tabular}{|c|c|c|c|c|}
\hline & & \multicolumn{3}{|c|}{ Cases - control comparison } \\
\hline & & Control & Azospermia & Oligospermia \\
\hline \multirow{4}{*}{ ASA } & \multirow{2}{*}{ Negative } & 25 & 19 & 21 \\
\hline & & $100.0 \%$ & $76.0 \%$ & $84.0 \%$ \\
\hline & \multirow{2}{*}{ Positive } & $\mathbf{0}$ & 6 & 4 \\
\hline & & $0.0 \%$ & $24.0 \%$ & $16.0 \%$ \\
\hline \multirow{2}{*}{\multicolumn{2}{|c|}{ Total }} & 25 & 25 & 25 \\
\hline & & $100.0 \%$ & $100.0 \%$ & $100.0 \%$ \\
\hline \multirow{3}{*}{\multicolumn{2}{|c|}{ P value }} & & 0.009 & 0.037 \\
\hline & & \multicolumn{3}{|c|}{ Cases - control comparison } \\
\hline & & Control & Azospermia & Oligospermia \\
\hline \multicolumn{5}{|c|}{ Serum IL-6 pg/ml } \\
\hline \multicolumn{2}{|c|}{ Range } & $6.4-10.3$ & $13.7-28.5$ & $8.7-28.5$ \\
\hline \multicolumn{2}{|c|}{ Mean \pm SD } & $8.65 \pm 0.76$ & $12.67 \pm \mathbf{5 . 9 7}$ & $10.92 \pm 5.22$ \\
\hline \multicolumn{2}{|c|}{ No. } & 25 & 25 & 25 \\
\hline \multicolumn{2}{|c|}{$P$ value } & & 0.002 & 0.037 \\
\hline
\end{tabular}

Table.4 Distribution of Seropositive and Seronegative for Ana in Infertile Males and Control Group

\begin{tabular}{|l|l|l|l|l|l|}
\hline \multirow{2}{*}{$\begin{array}{c}\text { Results } \\
\text { groups }\end{array}$} & \multicolumn{2}{|l|}{ Positive } & Negative & \multirow{2}{*}{ Total } \\
\cline { 2 - 5 } & No. & $\%$ & No. & $\%$ & \\
\hline Infertile & 1 & 2 & 49 & 98 & 50 \\
\hline Control & 0 & 0 & 25 & 100 & 25 \\
\hline$X^{2}=1.13$ & df $=1$ & P $>0.05$ & \\
\hline
\end{tabular}

In addition, Bohring et al. (2004) and Suri, (2005) have also stated that ASA in men may causes autoimmune disease when compromise the ability of the spermatozoa to migrate through the mucosa of the cervix by impaired by agglutinating antibodies and substantially eliminated by movement the antibodies in semen. In a more recent investigation, a significant association was found between ASA positive seminal plasma and testosterone concentration among infertile Jordanian cases, and the results suggested a "relationship between testicular steroid hormone levels with autoimmunity and sperm antibodies which may influence the motility of ejaculated spermatozoa among infertile males" (AlDaghistani et al., 2010).The ASA is important factor leading to disruption of hematotesticular barrier by prevent the spermatogenesis in the testicular mass. It is increased the risk of autoimmune disease. This result agreed with several studies, one of these done by Bozhedomov and Teodorovich, (2005) who found that ASA was present (35\%) in infertility male. Moreover, this study was agreement with other study perform by Bruce et al. (2005) who have stated that $32 \%$ ASA positive results among infertile men. While disagrees 
with other study suggested by Al- Janabi (2000) who found 14.8\% ASA positive among Azospermia and varicocele patients.

Distribution of ANA the Serum of Azospermic, Oligospermic and Control Group

Results of recent research revealed a low seropositive percent for ANA, the data obtained from Table (4), demonstrated there was no significant difference $(P>0.05)$ of ANA in studied group. In some cases, a person may have more than one autoimmune disease. For example, individuals with Addison disease often have infertility, while those with sclerosing cholangitis often have ulcerative colitis (AACC, 2015). The present study found no relation between ANA and Infertility, which agreed with (Denman, 2009).

In conclusion, there was significantly percentage of anti-sperm auto antibodies among patients with infertile male in comparison with fertile control. This provides strong evidence that autoimmunity plays a major role in the pathogenesis of infertility. Male infertility susceptibility in most Najaf patients was associated with the HLADQB1*03 genotype for Azospermia, the HLA-DRB $1 * 03$ allele contributed significantly to the development infertility. While HLA DQB1*05 allele occur in Oligospermia. Therefore, HLADRB $1 * 03$ \&* 05 allele may be appears to play an important pathogenic role in infertility. The results conducted to the elevation level cytokine including IL-6 and ASA have significant correlation with Oligospermia \& Azospremia.

\section{References}

Ad'hiah, A.H. 2011. Distribution of HLA polymorphism in a sample of Iraqi
Arabs in comparison with three Arab Gulf populations. Iraqi J. Sci., 50: 120125.

Al -Yasiri, I.K.H. 2012. Evaluation of Some Immunological and Molecular Techniques for Early Diagnosis of Rheumatoid Arthritis. PhD. thesis.Faculty medicin - University of KUFA. Iraq.

Al-Daghistani, H.I., Hamad, A.R., AbdelDayem, M., Al-Swaifi, M. and Abu Zaid, M. 2010. Evaluation of serum testosterone, progesterone, seminal antisperm antibody, and fructose levels among Jordanian males with a history of infertility. Biochem. Res. Int., 409640.

Aleksovski, D., Todorov, Z., Chilimanov, Z. 1988. Possibilities of association of azoospermia and oligospermia with some HLA system antigens. Human Reproduction, 3: 83-84.

Al-Janabi, H.A. 2000. Antisperm antibody in individuals with unexplained infertility: Freguency and treatment. Msc, thesis, collage of medicine, Tikrit University, Iraq. 70-76.

Andrews, A.L., Nordgren, I.K., Kirby, I., Holloway, J.W., Holgate, S.T., Davies, D.E., Tavassoli, A. 2009. Cytoplasmic tail of IL-13R $\alpha 2$ regulates IL-4 signal transduction. Biochem. Soc. Transactions, 37: 873-876.

Avendaño, C., Franchi, A., Jones, E., Oehninger, S. 2008. Pregnancy-specific $\beta$-1-glycoprotein 1 and human leukocyte antigen-E mRNA in human sperm: differential expression in fertile and infertile men and evidence of a possible functional role during early development. Human Reproduction, 24 270-277.

Bao, X., Wang, W.J., Dai, N. 2011. Study of the correlation between 51 immune infertility patients of the Han nationality in Anhui and HLA-DQA1 gene and treatment of Mianbu III. Zhongguo 
Zhong Xi Yi Jie He Za Zhi, 31: 334-337.

Bohring, C., Klepper, L., Krause, W. 2004. Localization of binding sites of naturally occurring antisperm antibodies on human spermatozoa by immunofluoresence. Andrologia, 36: 286-290.

Bosmans, E., Comhaire, F.H. 2003. Cytokines in semen of normal men and of patients with andrological disease. The American Fertility Society conjointly with Canadian Fertility and Andrology Society 11-14 October 2003, Montreal, Canada. Fertil. Steril., (Program suppl.) S44-5.

Bozhedmov, V.A., Teodorovich, O.V. 2005. Epidemiology and causes of autoimmune male infertility. Urologiia, (1): 35-44.

Brackett, N.L., Lynne, C.M., Aballa, T.C., Ferrell, S.M. 2000. Sperm motility from the vas deferens of spinal cord injured men is higher than from the ejaculate. $J$. Urol., 164: 712-715.

Bruce, R., Gilbert, M.D., Steven, S., Witkin, M., Goldstein, D. 2005. Immunology of Male Infertility, Population Council, NewYork hospital: Cornell University Medical Center. pp. 1-11.

Brugh, V.M., Lipshultz, L.I. 2004. Male factor infertility. Med. Clin. North Amer., 88(2): 367-85.

Celińska, A., Fracki, S., Sangidorj, D., Barcz, E. 2006. Role of inflammatory cytokines in male infertility. Ginekologia Polska, 77: 404-411.

Chiu, W.W., Chamley, L.W. 2004. Clinical associations and mechanisms of action of antisperm antibodies. Fertil. Steril., 82: 529-35.

De Almeida, D.E., Holoshitz, J. 2011. MHC molecules in health and disease. Self Nonself Immune Recognition and Signaling, 2: 43-48.

Eggert, W.J., Bronson, R., Cooper, G., Rosenfeld, D. 2000. Sperm antibodies: their role in infertility. Fertil. Steril., 42: 171-183.

Feng, H.L., Han, Y.B., Sparks, A.E.T., Sandlow, J.I. 2008. Characterization of Human Sperm Antigens Reacting with Anti-Sperm Antibodies from an Infertile Female Patient's Serum. $J$. Androl., Vol. 29, No. 4, July/August.

Ferguson-Smith, A.C., Chen, Y.F., Newman, M.S., May, L.T., Sehgal, P.B., Ruddle, F.H. 1998. Regional localization of the interferon-beta 2/Bcell stimulatory factor 2/hepatocyte stimulating factor gene to human chromosome 7p15-p21. Genomics, 2(3): 203-208.

Hedger, M.P., Meinhardt, A. 2003. Cytokines and the immune-testicular axis. J. Reproductive Immunol., 58: 126.

Hedges, J.C., Singer, C.A., Gerthoffer, W.T. 2000. Mitogen-activated protein kinases regulate cytokine gene expression in human airway myocytes. Am. J. Respir. Cell Mol. Biol., 23(1): 86-94.

Hirano, T., Kishimoto, T. 2004. Interleukine-6, in piptide Growth factor and their Recetors, part 1( eds M.B sporn and A.B Roberts ), SpringerVerlag. New York. pp. 633-66.

Khatoon, M., Chaaudhari, A.R., Singh, R. 2012. Effect of gender on antisperm antibodies in infertile couple in central India. 12 n6d2iank hja tpohoyns ieotl palharmacpl, 56(3): 262-266.

Martin-Villa, J.M., Longas, J., ArnaizVillena, A. 1999. Cyclic expression of HLA class I and II molecules on the surface of purified human spermatozoa and their control by serum inhibin B levels. Biol. Reproduction, 61: 13811386.

Matsuzaka, Y., Makino, S., Okamoto, K., Oka1, A., Tsujimura, A., Matsumiya, K., Takahara, S., Okuyama, A., Sada, M., Gotoh, R., Nakatani, T., Ota, M., 
Katsuyama, Y., Tamiya, G., Inoko, H. 2004. Susceptibility locus for nonobstructive azoospermia is localized within the HLA-DR/DQ subregion: Primary role of DQB1*0604. Tissue Antigens Immune Response Genetics, 1: 53-63. McGranw H.San Francisco, 678-712.

Menkveld, R., Holleboom, C.A.G., Rhemrev, J.P.T. 2011. Measurementand significance of sperm morphology. Asian J. Androl., 13: 59-68.

Miura, H., Tsujimura, A., Nishimura, K., Kitamura, M., Kondoh, N., Takeyama, M., Fujioka, H., Sada, M., Tsuji, T., Matsumiya, K., Takahara, S., Okuyama, A. 1998. Susceptibility to idiopathic azoospermia in Japanese men is linked to HLA class I antigen. J. Urol., 159: 1939-1941.

Naz, R.K., Kaplan, P. 2004. Increased levels of IL 6 in seminal plasma of infertile male. J. Androl., 15: 220-7.

Robinson, J., Mistry, K., McWilliam, H., Lopez, R., Parham, P., Marsh, S.G. 2011. The IMGT/HLA database. Nucleic Acids Research, 39: D11711176.

Said, M.T. 2008. Emotional stress and male infertility. Ind. J. Med. Research, 128: 228-230.

Shen, C., Zhu, B., Liu, M., Li, S. 2008. Genetic polymorphisms at HLA-A, -B, and -DRB1 loci in Han population of Xi'an city in China. Croatian Med. J., 49: 476-482.

Suri, A. 2005. Contraceptive vaccines targeting sperm. Expert Opinion on Biol. Therapy, 3: 381-392.

Takao, T., Tsujimura, A., Sada, M., Goto,
R., Koga, M., Miyagawa, Y., Matsumiya, K., Yamada, K., Takahara, S., Okuyama, A. 2004. Susceptibility gene for non-obstructive azoospermia in the HLA class II region: correlations with Y chromosome microdeletion and spermatogenesis. Int. J. Androl., 27: 3741.

Tsujimura, A., Takahara, S., Kitamura, M., Miura, H., Koga, M., Sada, M., Tsuji, T., Matsumiya, K., Okuyama, A. 1999. HLA-DR antigen and HLA-DRB1 genotyping with nonobstructive azoospermia in Japan. J. Androl., 4: $545-550$.

WHO. 2010. Laboratory Manual for the examination of human semen and semen cervical mucus nteraction. WHO. Cambridge Unversity Press, 3rd Ed.

Yang, G., Deng, Y.J., Qin, H., Zhu, B.F., Chen, F., Shen C.M., Sun, Z.M., Chen, L.P., Wu, J., Mu, H.F., Lucas, R. 2010. HLA-B*15 subtypes distribution in Han population in Beijing, China, as compared with those of other populations. Int. J. Immunogenetics, 37: 205-212.

Zhou, D.X., Wang, X.F., Zhang, J., Wang, H., Tian, Z. 2011. Association study of human leukocyte antigen-A gene with idiopathic male infertility in Han population of chaina. Andrologia, (In press).

Zhou, D.X., Zhang, J., Wang, H.X., Wang, X.F., Tian, Z., Zhao, W.B., Han, S.P., Zhang, J., Huo, Y.W., Tian, H. 2011. Association study of HLA-B alleles with idiopathic male infertility in Han population of chaina. J. Assisted Reproduction and Genetics, (In press).

\section{How to cite this article:}

Hammadi A. Al-Hilali and Haider J. Al-hasani. 2016. Role of HLA-DQ Genotyping with Some Immunological Markers in Susceptibility for Infertile Males in Najaf Province. Int.J.Curr.Microbiol.App.Sci. 5(3): 277-287. doi: http://dx.doi.org/10.20546/ijcmas.2016.503.034 